\title{
PENYERAPAN ION LOGAM Pb(II) DARI LARUTAN MENGGUNAKAN SERBUK DAUN PURING (Codiaeum variegatum)
}

\author{
Fitriani $^{1}$, Tuti Kurniati ${ }^{1}$ dan Hambali $^{1}$ \\ ${ }^{1}$ Prodi Pendidikan Kimia FKIP Universitas Muhammadiyah Pontianak \\ Jl. Ahmad Yani No. 111 Pontianak Kalimantan Barat \\ E-mail: bungafi3ani@gmail.com
}

\begin{abstract}
The adsorption of metal ion $\mathrm{Pb}(\mathrm{II})$ by croton leaf powder through the activation of hydrochloric acid $(\mathrm{HCl})$ or chemical methods has been researched. The research aimed to determine the optimum condition of croton leaf powder as adsorbent by variation of contacting time (30,60, 90 and 120 minutes) and the difference in mass of adsorbent (1;2; 3 and 4 grams ). This research began with downsizing the size of croton leafs become to 100 mesh, then was performed chemical activation by soaking the croton leaf powder with $2 \mathrm{~N} \mathrm{HCl}$. The adsorption was conducted by contacting the adsorbent with a solution of the sample based on contacting time and mass of adsorbent, then analyzed by Atomic Absorption Spectrophotometer (AAS). The result showed that the optimum condition of adsorption was achieved at 4 grams adsorbent by contacting time in the 60 minutes with $\mathrm{Pb}(\mathrm{II})$ adsorbed $1,76 \mathrm{mg} / \mathrm{L}$ or 35,2\%. Based on this findings, we concluded that the increase in mass of adsorbent increased the adsorption power of metal ion $\mathrm{Pb}(\mathrm{II})$ by optimum contacting time.
\end{abstract}

Keywords: adsorption, croton leaf powder, metal ion Pb(II)

Salah satu masalah yang dialami oleh negara berkembang adalah pencemaran. Cemaran dapat berasal dari alam maupun dari perbuatan manusia, yang dapat menyebabkan terganggunya ekosistem di lingkungan. Salah satu jenis cemaran yang harus mendapat perhatian adalah logam-logam berat. Secara umum diketahui bahwa logam berat merupakan unsur yang berbahaya, sehingga kontaminasi logam berat di lingkungan merupakan masalah besar. Permasalahan spesifik logam berat di lingkungan adalah terakumulasinya sampai pada rantai makanan tingkat tertinggi, serta meningkatnya sejumlah logam berat, yang menyebabkan peningkatan keracunan pada tanah, udara dan air.

Beberapa unsur logam berat yang dihasilkan oleh proses industri antara lain merkuri $(\mathrm{Hg})$, timbal $(\mathrm{Pb})$, tembaga $(\mathrm{Cu})$, kromium $(\mathrm{Cr})$, kadmium $(\mathrm{Cd})$, air raksa $(\mathrm{Hg})$, nikel (Ni), seng (Zn) dan arsen (As). Timbal merupakan salah satu logam berat yang sangat berbahaya dan dapat menyebabkan keracunan pada makhuk hidup serta tidak dapat 
terurai oleh proses alam (Deri dan Afu., 2013). Sumber utama timbal yang masuk ke lingkungan berasal dari limbah industri seperti industri baterai, industri bahan bakar, pengecoran maupun pemurnian dan industri kimia lainnya (Sudarmadji, dkk., 2006). Polutan logam berat tersebut dapat menimbulkan resiko yang sangat berbahaya bagi makhluk hidup apabila dibuang langsung ke lingkungan. Timbal dapat masuk ke dalam tubuh manusia melalui pernapasan, makanan, dan air yang terkontaminasi oleh logam timbal, serta absorpsi melalui kulit (Supriharyono, 2000). Secara alamiah timbal dapat berada dalam badan perairan dengan kadar 0,002-0,010 ppm. Timbal ini diperoleh dari aktivitas manusia dan berasal dari pembakaran bahan bakar motor serta emisi mobil (Mahmoud et al., 2010). Kadar maksimum timbal pada perairan yang dibatasi oleh World Health Organization (WHO) adalah kurang dari 0,01 ppm (Ensafi and Shiraz, 2008).

Upaya mengurangi pencemaran logam berat timbal $(\mathrm{Pb})$ yang semakin meningkat di lingkungan, diarahkan pada penggunaan bahan yang mudah didegradasi. Beberapa metode kimia maupun biologis telah dicoba untuk menghilangkan logam berat yang terdapat di dalam lingkungan maupun perairan, di antaranya adsorpsi, pertukaran ion (ion exchange) dan pemisahan dengan membran (Hariani, dkk., 2009). Di antara metode-metode tersebut, adsorpsi merupakan metode yang paling umum dipakai karena memiliki konsep yang lebih sederhana dan dapat diregenerasi serta ekonomis.
Proses adsorpsi terjadi pada permukaan pori-pori dalam adsorben, sehingga untuk bisa teradsorpsi, logam dalam cairan mengalami proses perpindahan massa logam dari cairan ke permukaan adsorben (Qaiser et al., 2007). Saat ini telah banyak dikembangkan berbagai jenis adsorben. Salah satunya adalah penggunaan daun sebagai adsorben. Penggunaan daun sebagai adsorben yang telah ada di antaranya adalah penggunaan daun jambu biji untuk mengadsorpsi logam $\mathrm{Cd}$ dengan kapasitas adsorpsi 3,99 mg/g (Varma et al., 2010), penggunaan daun duwet (Syzygium cumini L) untuk mengadsorpsi logam $\mathrm{Pb}$ dengan kapasitas adsorpsi 21,77 mg/g (King et al., 2006), penggunaan daun nimba untuk mengadsorpsi logam $\mathrm{Cr}$ dengan kapasitas adsorpsi 62,97 mg/g (Babu and Gupta, 2007), dan penggunaan daun mangga untuk mengadsorpsi logam $\mathrm{Cu}$ dengan kapasitas adsorpsi 206,85 mg/g (Sethu et al., 2010). Penelitian sejenis menggunakan daun puring masih jarang ditemui. Pada penelitian ini daun puring digunakan untuk mengadsorpsi logam $\mathrm{Pb}$ dengan penambahan perlakuan daun puring yang diberi larutan asam klorida $(\mathrm{HCl})$.

Puring dikenal dengan nama Croton, digunakan sebagai tanaman hias karena keindahan keragaman corak dan warnanya. Selain itu, puring juga digunakan sebagai tanaman penyerap polutan. Daun puring terdapat kandungan kimia seperti saponin, tannin dan pada daunnya banyak terdapat stomata yang efektif menyerap timbal $(\mathrm{Pb})$ yang ada di udara (Setiawan, 2014). Hasil penelitian Dewi dan Indri 
(2012) menyatakan bahwa daun puring mampu menyerap $\mathrm{Pb}$ di udara ambien sebanyak $0,55 \mathrm{mg} / \mathrm{kg}$. Tinggi rendahnya kadar $\mathrm{Pb}$ yang terserap tergantung pada jenis daun yang memiliki permukaan kasar dan daun yang lebar.

Berdasarkan latar belakang penjelasan di atas, penulis merasa perlu dan tertarik untuk melakukan penelitian mengenai peranan serbuk daun puring sebagai penyerap ion logam $\mathrm{Pb}$ (II) dari larutannya. Penelitian ini bertujuan mengukur pengaruh massa dan waktu kontak optimum adsorpsi ion logam $\mathrm{Pb}$ (II) dari adsorben yang berasal dari tanaman hias yaitu puring.

\section{METODE PENELITIAN}

\section{Alat dan Bahan}

Adapun alat-alat yang digunakan dalam penelitian ini adalah alat-alat gelas, ayakan 100 mesh, $\mathrm{pH}$ meter Hanna Instrument model 19208 dan seperangkat Spektrofotometer Serapan Atom (SSA) Shimadzu 6800.

Adapun bahan-bahan yang digunakan dalam penelitian ini adalah serbuk daun puring, larutan $\mathrm{HCl} 2 \mathrm{~N}$, serbuk $\mathrm{Pb}\left(\mathrm{NO}_{3}\right)_{2}, \quad$ kertas saring, aquadest, aluminium foil, dan kertas label.

\section{Prosedur Penelitian \\ Preparasi Adsorben Serbuk Daun Puring}

Tahap pertama yaitu preparasi sampel, daun puring dicuci bersih pada air yang mengalir untuk menghilangkan debu dan pengotor. Setelah itu daun puring dianginanginkan sampai kering selama beberapa hari. Daun puring yang telah kering dihaluskan dengan cara diblender tanpa pelarut, kemudian diayak sehingga ukurannya lolos pada ayakan 100 mesh. Serbuk yang dihasilkan selanjutnya diaktivasi.

Aktivasi serbuk daun puring dengan larutan $\mathrm{HCl} 2 \mathrm{~N}$

Dalam labu erlenmeyer 100 $\mathrm{mL}$ dimasukkan sampel serbuk daun puring, kemudian dicampur dengan larutan $\mathrm{HCl} 2 \mathrm{~N}$. Selanjutnya diaduk selama 2 jam menggunakan magnetic stirrer. Campuran didiamkan selama 24 jam dan dilanjutkan dengan pencucian berkali-kali menggunakan aquades sampai $\mathrm{pH}$ antara 6-8 yang diuji dengan menggunakan $\mathrm{pH}$ meter/kertas lakmus. Serbuk daun puring yang dihasilkan selanjutnya dikeringkan dalam oven pada suhu 60 ${ }^{0} \mathrm{C}$ selama 24 jam. Kemudian disimpan dalam desikator untuk menjaga agar serbuk daun puring tetap dalam kondisi kering.

\section{Penentuan Massa Optimum} Adsorpsi Ion Logam Pb(II)

Sebanyak $50 \mathrm{~mL}$ larutan $\mathrm{Pb}\left(\mathrm{NO}_{3}\right)_{2}$ dengan konsentrasi awal 5 ppm diinteraksikan dengan variasi massa adsorben yang telah lolos ayakan 100 mesh sebanyak 1, 2, 3, dan 4 gram. Dilakukan pengadukan dengan kecepatan $100 \mathrm{rpm}$ selama waktu kontak optimum menggunakan magnetic stirrer. Campuran kemudian disaring dan filtratnya diuji dengan SSA pada panjang gelombang 283,3 nm. Sehingga diperoleh massa optimum adsorben. Jumlah ion logam $\mathrm{Pb}(\mathrm{II})$ yang teradsorpsi dihitung dari selisih antara konsentrasi ion logam $\mathrm{Pb}$ (II) dalam larutan awal dengan konsentrasi ion logam $\mathrm{Pb}$ (II) dalam filtrat.

\section{Penentuan Waktu Kontak Optimum Adsorpsi Ion Logam $\mathrm{Pb}(\mathrm{II})$}

Sebanyak $50 \mathrm{~mL}$ larutan $\mathrm{Pb}\left(\mathrm{NO}_{3}\right)_{2}$ dengan konsentrasi awal 5 
ppm diinteraksikan dengan massa adsorben optimum yang telah lolos ayakan 100 mesh. Dilakukan pengadukan dengan kecepatan 100 rpm dalam variasi waktu kontak yaitu $30, \quad 60, \quad 90$ dan 120 menit menggunakan magnetic stirrer. Campuran kemudian disaring dan filtratnya diuji dengan SSA pada panjang gelombang 283,3 $\mathrm{nm}$. Sehingga diperoleh waktu kontak optimum. Jumlah ion logam $\mathrm{Pb}$ (II) yang teradsorpsi dihitung dari selisih antara konsentrasi ion logam $\mathrm{Pb}$ (II) dalam larutan awal dengan konsentrasi ion logam $\mathrm{Pb}$ (II) dalam filtrat.

\section{HASIL DAN PEMBAHASAN Preparasi Adsorben Serbuk Daun Puring}

Penelitian ini diawali dengan pembuatan serbuk daun puring sebagai adsorben untuk penyerapan ion logam $\mathrm{Pb}(\mathrm{II})$ dari larutan. Preparasi bahan baku pembuatan serbuk daun puring meliputi pencucian dan pengeringan. Proses pengeringan sampel dilakukan dengan cara diangin-anginkan tanpa paparan sinar matahari secara langsung. Hal ini bertujuan agar senyawa aktif dalam sampel tidak mengalami kerusakan dan kadar air dalam sampel berkurang. Selain sampel lebih awet, pengurangan kadar air akan memudahkan pelarut menarik komponen bioaktif dalam sampel saat maserasi (Sudirman dkk, 2011)

Selanjutnya daun puring dipotong kecil-kecil untuk mereduksi ukurannya. Daun puring kemudian diblender dan dihaluskan dengan ayakan yang berukuran hingga 100 mesh. Hal ini dilakukan agar proses penyerapan adsorbat oleh adsorben lebih cepat karena semakin kecil ukuran partikel, maka luas permukaan adsorben akan bertambah luas sehingga logam akan semakin banyak yang terserap pada permukaan adsorben (Sunarya, 2006).

\section{Aktivasi Serbuk Daun Puring dengan Larutan HCl 2 N}

Pada proses aktivasi adsorben, serbuk daun puring diaduk selama 2 jam dengan activator larutan $\mathrm{HCl} 2 \mathrm{~N}$ dan didiamkan selama 24 jam. Aktivasi adsorben bertujuan untuk mendekomposisikan garam-garam mineral yang terdapat pada sampel seperti kalsium yang berikatan dengan adsorben (Safrianti dkk, 2012). Berkurangnya garam-garam mineral tersebut mengindikasikan terbentuknya gugus fungsi seperti $\mathrm{COOH}$ dan $-\mathrm{OH}$ pada adsorben sehingga nantinya akan lebih banyak ion logam $\mathrm{Pb}$ yang diadsorpsi oleh adsorben melalui pertukaran ion maupun pertukaran kompleks. Selanjutnya adsorben serbuk daun puring dikeringkan dalam oven pada suhu $60{ }^{\circ} \mathrm{C}$ selama 24 jam. Menurut Cavalcante., et al (2005), pemanasan dengan suhu tinggi dapat mengakibatkan penyusutan volume dan penutupan pori-pori adsorben, sehingga dapat mengurangi kapasitas adsorpsi adsorben terhadap logam.

\section{Penentuan Massa Optimum Adsorpsi Ion Logam Pb(II)}

Pengaruh jumlah adsorben merupakan parameter penting adsorpsi karena dapat menentukan kapasitas adsorben selama penambahan konsentrasi awal adsorbat. Adanya peningkatan jumlah adsorben cenderung meningkatkan daya serap terhadap adsorbat (Bhattacharyya and Gupta, 2008). 
Variasi massa adsorben serbuk daun puring yang digunakan dalam penelitian ini adalah 1, 2, 3 dan 4 gram. Data hasil pengujian variasi massa adsorben serbuk daun puring ditunjukkan pada Tabel 1.

Tabel 1. Konsentrasi $\mathrm{Pb}(\mathrm{II})$ yang Teradsorpsi dan Efisiensi dengan Variasi Massa Adsorben

\begin{tabular}{|c|c|c|c|c|}
\hline \multicolumn{5}{|c|}{ Adsorben } \\
\hline \multirow{3}{*}{ Massa } & Wak & Konsen & $\mathrm{Pb}$ & $\%$ \\
\hline & Kon & & Ter & $\mathrm{Pb}$ \\
\hline & tak & Akhir & $\begin{array}{c}\text { adsor } \\
\text { psi }\end{array}$ & \\
\hline (gram) & (t) & $(\mathrm{mg} / \mathrm{L})$ & $\begin{array}{c}(\mathrm{mg} / \\
\mathrm{L})\end{array}$ & $\begin{array}{l}\text { Terad } \\
\text { sorpsi }\end{array}$ \\
\hline 1,0 & 60 & 4,48 & 0,52 & 10,4 \\
\hline 2,0 & 60 & 4,21 & 0,79 & 15,8 \\
\hline 3,0 & 60 & 3,61 & 1,39 & 27,8 \\
\hline 4,0 & 60 & 3,24 & 1,76 & 35,2 \\
\hline
\end{tabular}

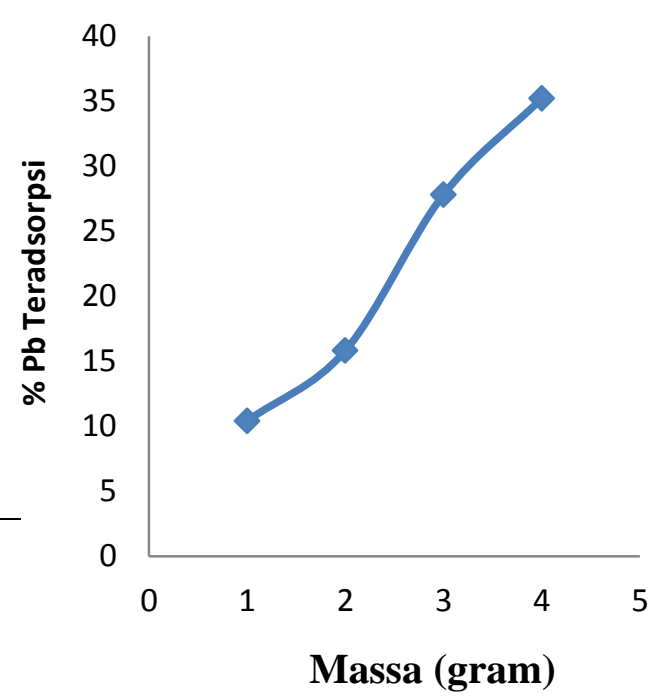

Gambar 1. Grafik Penentuan Massa Optimum berdasarkan $\% \mathrm{~Pb}$ Teradsorpsi

Hasil tersebut terlihat pada Gambar 1, menunjukkan bahwa hubungan antara massa adsorben

Berdasarkan Tabel 1. dalam penentuan massa optimum menunjukkan adanya peningkatan \% $\mathrm{Pb}$ teradsorpsi dalam variasi massa adsorben. Proses adsorpsi ion logam $\mathrm{Pb}$ (II) terjadi seiring dengan meningkatnya massa adsorben serbuk daun puring dari massa 1 gram sampai 4 gram. Hal tersebut menunjukkan bahwa massa adsorben berpengaruh terhadap proses adsorpsi karena semakin bertambahnya massa adsorben maka nilai \% $\mathrm{Pb}$ teradsorpsi juga semakin meningkat dan mencapai kesetimbangan. dengan $\% \mathrm{~Pb}$ teradsorpsi berbanding lurus, dimana semakin tinggi massa adsorben yang digunakan maka \% efektivitas adsorpsi logam semakin tinggi. Sehingga massa adsorben serbuk daun puring 4 gram ditetapkan sebagai massa optimum yang dikontakkan selama 60 menit dengan jumlah $\mathrm{Pb}(\mathrm{II})$ teradsorpsi sebesar $1,76 \mathrm{mg} / \mathrm{L}$ dan $\% \mathrm{~Pb}$ teradsorpsi sebesar $35,2 \%$. Hal tersebut sesuai dengan hasil penelitian yang dilakukan oleh Krisnawati dkk (2013) dimana konsentrasi ion logam akan semakin menurun dengan bertambahnya jumlah adsorben yang 
digunakan. Jumlah adsorben yang semakin banyak akan memperluas penyerapan ion logam yang ada pada suatu larutan sehingga \% efektivitas adsorpsi juga akan semakin meningkat.

\section{Penentuan Waktu Kontak Optimum Adsorpsi Ion Logam $\mathbf{P b}(\mathrm{II})$}

Waktu merupakan salah satu faktor yang mempengaruhi proses adsorpsi. Waktu adsorpsi atau waktu kontak adalah waktu yang digunakan adsorben untuk mengadsorpsi adsorbat dan berpengaruh terhadap daya adsorpsi. Adsorpsi ion dari suatu zat terlarut akan meningkat apabila waktu kontaknya semakin lama. Waktu kontak yang lama memungkinkan difusi dan penempelan molekul zat terlarut yang teradsorpsi berlangsung lebih banyak. Waktu untuk mencapai keadaan setimbang pada proses serapan logam oleh adsorben berkisar antara beberapa menit hingga beberapa jam (Khasanah, 2009).

Penelitian penentuan optimasi waktu kontak adsorpsi bertujuan untuk mengetahui berapa waktu yang dibutuhkan untuk mencapai kesetimbangan yang optimum. Penentuan waktu kontak optimum dilakukan pada adsorben serbuk daun puring terhadap ion logam $\mathrm{Pb}$ (II) melalui variasi waktu kontak 30, 60, 90 dan 120 menit dengan massa adsorben optimum 4 gram. Pengaruh waktu kontak terhadap \% $\mathrm{Pb}$ teradsorpsi ditunjukkan pada Tabel 2.

Tabel 2. menunjukkan jumlah ion logam $\mathrm{Pb}(\mathrm{II})$ yang teradsorpsi meningkat seiring dengan bertambahnya waktu kontak. Waktu kontak pada menit ke-30 dan ke-60 jumlah ion logam $\mathrm{Pb}$ (II) yang teradsorpsi masing-masing sebesar 1,44 dan 1,76 mg/L. Waktu kontak pada menit ke-90 dan ke-120 cenderung mengalami penurunan pada jumlah ion logam $\mathrm{Pb}(\mathrm{II})$ yang teradsorpsi, masing-masing sebesar 0,66 dan $0,78 \mathrm{mg} / \mathrm{L}$.

Tabel 2. Konsentrasi $\mathrm{Pb}(\mathrm{II})$ yang Teradsorpsi dan Efisiensi dengan Variasi Massa Adsorben

\begin{tabular}{|c|c|c|c|c|}
\hline \multirow{3}{*}{ Massa } & $\begin{array}{c}\text { Wak } \\
\text { Tu }\end{array}$ & $\begin{array}{l}\text { Kon } \\
\text { sen } \\
\end{array}$ & $\mathrm{Pb}$ & $\%$ \\
\hline & Kon & $\mathrm{Pb}$ & Ter & $\mathrm{Pb}$ \\
\hline & Tak & $\begin{array}{l}\text { Ak } \\
\text { hir }\end{array}$ & $\begin{array}{c}\text { adsor } \\
\text { psi }\end{array}$ & \\
\hline (gram) & (t) & $\begin{array}{c}(\mathrm{mg} / \\
\mathrm{L})\end{array}$ & $\begin{array}{c}(\mathrm{mg} / \\
\mathrm{L})\end{array}$ & $\begin{array}{l}\text { Terad } \\
\text { sorpsi }\end{array}$ \\
\hline 4,0 & 30 & 3,56 & 1,44 & 28,8 \\
\hline 4,0 & 60 & 3,24 & 1,76 & 35,2 \\
\hline 4,0 & 90 & 4,34 & 0,66 & 13,2 \\
\hline 4,0 & 120 & 4,22 & 0,78 & 15,6 \\
\hline
\end{tabular}

Hasil tersebut terlihat pada Gambar 2, grafik hubungan antara waktu kontak dengan $\% \quad \mathrm{~Pb}$ teradsorpsi. Dari gambar tersebut terlihat bahwa semakin lama waktu kontak semakin tinggi efisiensi penyerapan, namun pada waktu 90 sampai 120 menit grafik menurun. Hal ini menandakan bahwa waktu kontak optimum serbuk daun puring dalam menyerap ion logam $\mathrm{Pb}$ (II) dicapai pada waktu 60 menit dengan jumlah $\mathrm{Pb}$ (II) teradsorpsi sebesar 1,76 $\mathrm{mg} / \mathrm{L}$ dan $\% \mathrm{~Pb}$ teradsorpsi sebesar $35,2 \%$. 


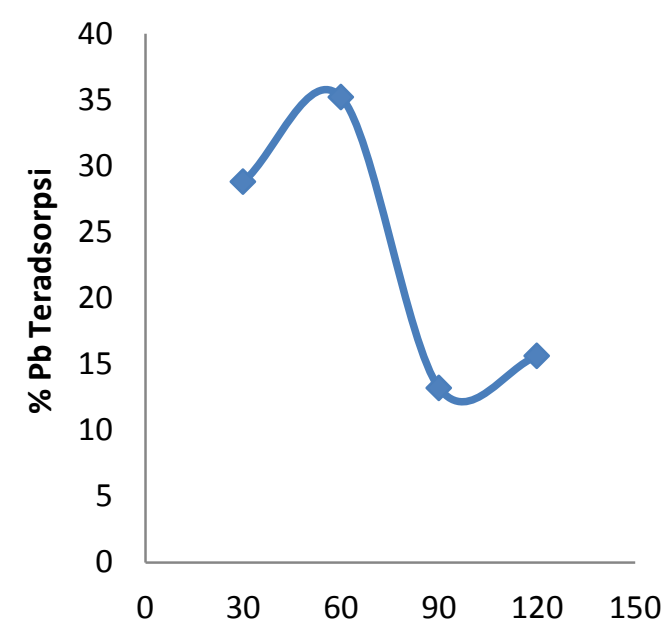

Waktu Kontak (menit)

Gambar 2. Grafik Penentuan Waktu Optimum berdasarkan \% $\mathrm{Pb}$ Teradsorpsi

Penurunan laju adsorpsi diakibatkan oleh kemampuan adsorben dalam mengadsorpsi logam semakin berkurang hingga pada waktu tertentu adsorben tidak dapat menyerap logam lagi yang ditunjukkan oleh penurunan kapasitas adsorpsi. Hal ini disebabkan oleh sisi aktif dari adsorben sudah terisi oleh logam hingga adsorbennya jenuh dan tidak mampu lagi menyerap logam (Emelda dkk, 2013).

\section{SIMPULAN DAN SARAN}

Berdasarkan hasil penelitian yang telah diperoleh dapat disimpulkan sebagai berikut :

1. Proses adsorpsi serbuk daun puring sebagai adsorben ion logam $\mathrm{Pb}(\mathrm{II})$ pada larutan $\mathrm{Pb}\left(\mathrm{NO}_{3}\right)_{2}$ dengan konsentrasi awal 5 ppm menghasilkan massa adsorben optimum sebanyak 4 gram dan waktu kontak optimum selama 60 menit.
2. Pada proses adsorpsi serbuk daun puring sebagai adsorben ion logam $\mathrm{Pb}(\mathrm{II})$ untuk massa dan waktu kontak optimum menghasilkan jumlah $\mathrm{Pb}(\mathrm{II})$ teradsorpsi sebesar $1,76 \mathrm{mg} / \mathrm{L}$ dan $\% \mathrm{~Pb}$ teradsorpsi sebesar 35,2\%.

Dari hasil penelitian ini yang dapat disarankan sebagai berikut:

1. Perlu penambahan titik variasi massa dan lama kontak yang lebih besar sehingga dapat mencapai keadaan kesetimbangan.

2. Perlu dilakukan penelitian lanjutan dengan variasi yang lain seperti konentrasi dan $\mathrm{Ph}$ untuk mengetahui kemampuan adsorpsi serbuk daun puring dalam mengadorpsi logam berat.

DAFTAR PUSTAKA

Babu, B. V., dan Gupta, S. (2007). Adsorption of $\mathrm{Cr}(\mathrm{VI})$ Using Activated Neemleaves: Kinetic Studies. Springer Science and Business Media. New York.

Bhattacharyya, KG and Gupta, S.S. (2008). Immobilization of $\mathrm{Pb}$ (II), $\mathrm{Cd}(\mathrm{II})$ and $\mathrm{Ni}(\mathrm{II})$ Ions on Kaolinite and Montmorillonite Surfaces from Aqueous. Journal of Environmental Management. Vol.87, 45-58.

Cavancante, J.A., Rocha, S.C.S and Luzio, M. (2005). Change in Structure of Marine Algae Sargassum sp. During Drying. $\quad 4^{\text {th }}$ Mercusor Congress on Process Systems Engineering. Brazil. 
Deri, E dan Afu L.O.A., (2013). Kadar Logam Berat Timbal $(\mathrm{Pb})$ pada Akar Mangrove Avicennia marina di PerairanTeluk Kendari. $J$. Mina Laut Indonesia, Vol.1, No.1, 38-48.

Dewi, Y.S dan Indri, H. (2012). Kajian Efektivitas Daun Puring (Codiaeum variegatum) dan Lidah Mertua (Sansevieria trispasciata) dalam Menyerap Timbal di Udara Ambien. Universitas Satya Negara Indonesia, Vol.5, No.2.

Emelda, L., Putri, S. M., \& Ginting, S. B. (2013). Pemanfaatan Zeolit Alam Teraktivasi Untuk Adsorpsi Logam $\mathrm{Cr}^{3+}$. Jurnal Rekayasa Kimia dan Lingkungan, Vol.2, No.4, 166-172.

Ensafi, A.A and Shiraz, A.Z., (2008). On-line Separation and Preconcentration of Lead (II) by Solid Phase Extraction using Activated Carbon Loaded with Xylanol Orange and Its Determination by Flame Atomic Absorption Spectrofotometry. J. Hazard Mater, Vol. 150, 554-559.

Hariani, P. L., Nurlisa, H. dan Melly, O. (2009). Penurunan Konsentrasi Cr(IV) dalam Air dengan Koagulan $\mathrm{FeSO}_{4}$. Jurnal Penelitian Sains, Vol.12, No. 2.
Khasanah, E.N. (2009). Adsorpsi Logam Berat Menggunakan Karbon Aktif Termodifikasi Zinc Klorida. Oseana. Yogyakarta: Universitas Gajah Mada.

King, P., Rakesh, N., Beenalahari, S., Kumar, Y. P., and Prasad, V. S. R.K., (2006). Removal of Lead from Aqueous Solution using Syzygium cumini L.: Equilibrium and Kinetic Studies. Journal Environmental Pollution Control Engineering Andhra University, 340347.

Krisnawati, Jasinda dan Iriany. (2013). Penjerapan Logam Kadmium $\left(\mathrm{Cd}^{2+}\right)$ dengan Adsorben Cangkang Telur Bebek yang telah diaktivasi. Jurnal Teknik Kimia USU, Vol.2, No.3, 29-32.

Mahmoud, M.E., Osman, M.M., Hafez, O.F., Hegazi, A.H and Elmelegy, E., (2010). Removal and Preconcentration of Lead (II) and Other Heavy Metals from Water by Alumina Adsorbents Developed by Surface Adsorbed Dithizone. J. Desalination, Vol. 251, 123-130.

Qaiser, S., Saleem, A.R and Ahmed, M.M. (2007). Heavy Metal Uptake by Agro Based Waste Materials. Environmental Biotechno, Vol. 10, No.3, 1-8. 
Safrianti, I., Wahyuni, N dan Zaharah, T.A. (2012). Adsorpsi Timbal(II) Selulosa Limbah Jerami Padi Teraktivasi Asm Nitrat: Pengaruh pH dan Waktu. Jurnal Kimia Khatulistiwa, Vol. 1, No.1, 1-7.

Sethu, V.S., Goey, K. S., Iffah, F. R.,Khoo, M., and Andresen, J. M., (2010). Adsorption Characteristics of $\mathrm{Cu}$ (II) Ions in Aqueous Solutions Using Mangiferaindica (Mango) Leaf Biosorbent. Jornal of Environmental Research and Development.

Setiawan, A. (2014). Perbedaan Jenis Puring Oskar (Codiaeum varigatum) dan Puring Anting (Codiaeum affine) Terhadap Penyerapan Kadar Timbal (Pb). Gorontalo : UNG.

Sudarmaji., Mukono, H.J dan Corie, I.P. (2006). Teknologi Logam Berat B3 dan Dampaknya Terhadap Kesehatan. Jurnal
Kesehatan Lingkungan, Vol.2, No.2, 141.

Sudirman, S., Nurdjanah, Abdullah, A. (2011). Aktivitas Antioksidan dan Komponen Bioaktif Kangkung Air (Ipomoea aquatic forsk.). Skripsi. Bogor: Institut Pertanian Bogor.

Sunarya, I.A. (2006). Biosorpsi Logam Berat Pb(II) dan Cd(II) menggunakan Kulit Jeruk Siam (Citrus reticulate). Skripsi. Bogor: Institut Pertanian Bogor.

Supriharyono. (2002). Pelestarian dan Pengelolaan Sumber Daya Alam di Wilayah Pesisir Tropis. Jakarta: Gramedia Pustaka Utama.

Varma, D. S. N. R., Srinivas, C. H., Nagamani, C. H., Premsagara, T., dan Rajsekhar, M., (2010). Studies on Biosorption of Cadmium on Psidium guajava Leaves Powder Using Statistical Experimental Design. $J$. Chem. Pharm. Res. 